\title{
A simple method to improve adenoma detection rate during colonoscopy: Altering patient position
}

\author{
Aydın Şeref Köksal MD¹, İsmail Hakkı Kalkan MD², Serkan Torun MD¹, \\ İsmail Taşkıran $M D^{1}$, Erkin Öztaş $M D^{1}$, Ertuğrul Kayaçetin $M D^{1}$, Nurgül Şaşmaz $M D^{1}$
}

\begin{abstract}
AŞ Köksal, IH Kalkan, S Torun, et al. A simple method to improve adenoma detection rate during colonoscopy: Altering patient position. Can J Gastroenterol 2013;27(9):509-512.
\end{abstract}

BACKGROUND: Colonoscopy is currently considered to be the gold standard method for detecting and removing adenomatous polyps. However, tandem colonoscopy studies reveal a pooled polyp miss rate of $22 \%$.

OBJECTIVE: A prospective randomized trial was conducted to assess whether alteration of patient position during colonoscopy withdrawal increases the adenoma detection rate (ADR).

METHOD: The study group included 120 patients who presented for elective colonoscopic examination. After reaching the cecum, patients were randomly assigned in a 1:1 ratio to examination in either the left lateral position or other positions (left lateral position for the cecum, ascending colon and hepatic flexure; supine for transverse colon; and supine and right lateral position for splenic flexure, descending and sigmoid colon) first. Examination of the colon was performed segment by segment. The size, morphology and location of all polyps were recorded. Polyps were removed immediately after examination of a colon segment when all positions were completed. ADR and polyp detection rates (PDR) were calculated.

RESULTS: A total of 102 patients completed the study. Examination in the left lateral position revealed 66 polyps in 31 patients (PDR 30.3\%) and 42 adenomas in 24 patients (ADR 23.5\%). PDR increased to $43.1 \%$ (81 polyps in 44 patients) and the ADR to $33.3 \%$ (53 adenomas in 34 patients) after the colon was examined in the additional positions $(\mathrm{P}<0.001$ and $\mathrm{P}=0.002$, respectively). The increase in the number of adenomas detected was statistically significant in the transverse and sigmoid colon. The addition of position changes led to a $9.8 \%$ increase in the ADR in the transverse colon, splenic flexure, and descending and sigmoid colon. The frequency of surveillance interval was shortened in nine $(8.8 \%)$ patients after examination of the colon in dynamic positions.

CONCLUSION: Alteration of patient position during colonoscopy withdrawal is a simple and effective method to improve ADR.

Key Words: Adenoma detection rate; Adenomatous polyp; Colon; Colonoscopy

Oolorectal cancer (CRC) is one of the most common malignancies in Western countries including the United States. Colonoscopy is currently considered to be the gold standard method for detecting and removing precancerous adenomatous polyps. However, tandem colonoscopy studies reveal a pooled miss rate of $22 \%$ for polyps and $26 \%$ for adenomas $<5 \mathrm{~mm}$ in size (1). Various devices and methods have been used to improve the detection of adenomas during colonoscopy. Devices include high-definition white-light colonoscopy, cap-fitted colonoscopy, wide-angle colonoscopes and third-eye retroscopes (2-5). Methods include inspection of the colon during withdrawal for a longer duration ( $\geq 6 \mathrm{~min}$ ), increasing the adequacy of the bowel preparation with the use

\section{Une méthode simple pour améliorer le taux de détection d'adénomes pendant une coloscopie : modifier la position du patient}

\begin{abstract}
HISTORIQUE : La coloscopie est considérée comme la méthode de référence pour déceler et retirer des polypes adénomateux. Cependant, les études de coloscopie en tandem révèlent un taux regroupé d'échec de détection des polypes de $22 \%$.
\end{abstract}

OBJECTIF : Les chercheurs ont procédé à un essai aléatoire prospectif pour évaluer si la modification de la position du patient pendant le retrait du coloscope accroît le taux de détection d'adénomes (TDA).

MÉTHODOLOGIE : Le groupe à l'étude se composait de 120 patients qui se sont présentés en vue d'un examen coloscopique non urgent. Lorsque le coloscope atteignait le cæcum, les patients étaient divisés au hasard, dans un ratio de 1:1, pour commencer d'abord par la position latérale gauche ou par d'autres positions (position latérale gauche pour le cæcum, le côlon ascendant et l'angle hépatique, position couchée pour le côlon transverse, et position couchée et latérale droite pour l'angle splénique, le côlon descendant et le côlon sigmoïde). Les médecins ont effectué l'examen du côlon segment par segment. Ils ont consigné la dimension, la morphologie et le foyer de tous les polypes. Ils ont fait l'exérèse des polypes immédiatement après l'examen d'un segment du côlon, une fois consignés les résultats de toutes les positions. Les chercheurs ont calculé le TDA et le taux de détection de polypes (TDP).

RÉSULTATS : Au total, 102 patients ont terminé l'étude. L'examen dans la position latérale gauche a révélé la présence de 66 polypes chez 31 patients (TDP de 30,3\%) et de 42 adénomes chez 24 patients (TDA de 23,5\%). Le TDP est passé à 43,1\% (81 polypes chez 44 patients) et le TDA, à 33,3 \% (53 adénomes chez 34 patients), après l'examen du côlon dans les positions supplémentaires $(\mathrm{P}<0,001$ et $\mathrm{P}=0,002$, respectivement). L'augmentation du nombre d'adénomes décelés était statistiquement significative dans le côlon transverse et sigmoïde. Lajout des changements de position a suscité un accroissement de 9,8\% du TDA dans le côlon transverse, l'angle splénique et le côlon descendant et sigmoïde. La fréquence d'intervalle de surveillance a diminué chez neuf patients $(8,8 \%)$ après l'examen du côlon dans des positions dynamiques.

CONCLUSION : Le fait de modifier la position du patient pendant le retrait du coloscope est un moyen simple et efficace d'améliorer le TDA.

of split-dose preparations, use of antispasmodics and advanced endoscopic techniques such as chromoendoscopy and electronic mucosal enhancement, and participation of an additional observer during the screening colonoscopy (6-11).

Radiologists' experience with barium enema suggest that altering patient position in a manner that the area of interest is brought to its highest point causes gas to rise and replaces the fluid in that area, which in turn leads to adequate distension and better examination. Therefore, the hepatic flexure, transverse colon and the splenic flexure, and descending and sigmoid colon are best examined with the patient in the left lateral, supine and right lateral positions, respectively. In

${ }^{1}$ Department of Gastroenterology, Türkiye Yüksek İhtisas Hospital, ${ }^{2}$ Department of Gastroenterology, Krrkkale University Faculty of Medicine, Turkey

Correspondence: Dr İsmail Hakkı Kalkan, Attar Sokak 21/14 G.O.P. Çankaya 06700, Ankara, Turkey. Telephone 90-312-4376778,

fax90-312-4680088, e-mail drismailster@gmail.com

Received for publication March 31, 2013. Accepted May 12, 2013 


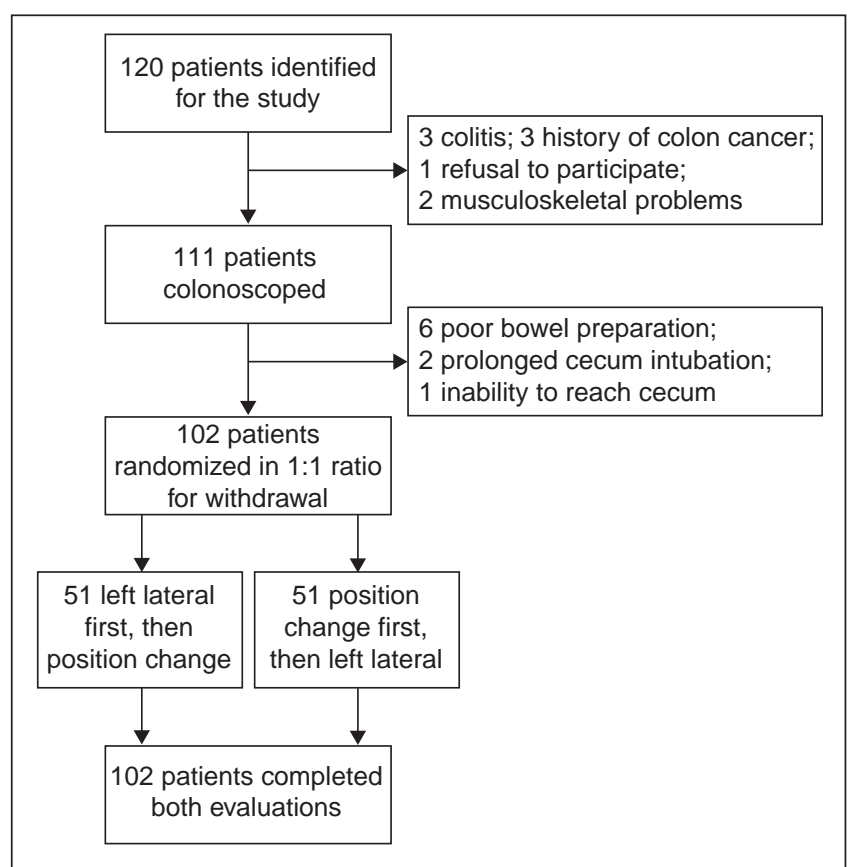

Figure 1) Participation of patients in the study

the present study, we conducted a randomized prospective trial to investigate whether these position changes defined for barium enema examination increase polyp and adenoma detection rates (PDR and ADR, respectively) during colonoscope withdrawal.

\section{Patients}

\section{METHODS}

The study group included 120 consecutive adult patients ( 40 to 80 years of age) who were admitted to Gastroenterology clinics of Türkiye Yüksek İhtisas Hospital (Ankara, Turkey) for elective outpatient colonoscopic examination. Patients with colitis, polyposis syndromes, history of colon operation, musculoskeletal problems, technical difficulty in reaching the cecum (time to intubate cecum $>20$ min or inability to reach cecum) or refused to participate in the study were excluded. All patients gave written informed consent to partipicate in the study, which was approved by the local ethics commitee.

\section{Colonoscopy examination}

All patients received a standard bowel preparation of $4 \mathrm{~L}$ of polyethylene glycol electrolyte lavage solution the night before colonoscopy. Colonoscopies were performed by a single experienced endoscopist. None of the patients received intravenous sedation or antispasmodics during colonoscopy as standard of care at the hospital. Colonoscopy was performed using Olympus Evis Lucera CF-Q260DL colonoscopes and an Olympus high-definition LCD monitor OEV191H (Olympus Medical System Corp, Japan). Room air was used to insufflate the bowel as the standard of care at the hospital.

During colonoscopy, fluid and debris were suctioned as much as possible during intubation. Bowel preparation quality was graded according to the Boston bowel preparation scale (12). Patients with a segment score $\leq 1$ were excluded from the study. Cecal intubation was confirmed by visualization of the ileocecal valve, the triradiate fold and the appendiceal orifice. After reaching the cecum, patients with acceptable bowel preparation were randomized according to a predetermined sequence in a 1:1 ratio to examination in either the left lateral position or other positions first.

The colon was subdivided into three regions: cecum, ascending colon and hepatic flexure; transverse colon; and splenic flexure, descending colon and sigmoid colon. The first region was examined in the left lateral position twice. The second region was examined in the left
TABLE 1

Demographic and clinical characteristics of the patients who completed the trial

\begin{tabular}{lc}
\hline Age, years, mean (range) & $57.1(40-82)$ \\
Sex, \% & 50 \\
Male & 50 \\
Female & $27.9 \pm 4.9$ \\
Body mass index, $\mathrm{kg} / \mathrm{m}^{2}$, mean $\pm \mathrm{SD}$ & $8.5(2-19)$ \\
Intubation time, min, mean (range) & \\
Indication, n (\%) & $31(30.4)$ \\
Colorectal cancer screening & $23(22.5)$ \\
Abdominal pain & $17(16.7)$ \\
Rectal bleeding & $11(10.8)$ \\
Constipation & $8(7.8)$ \\
Surveillance & $5(4.9)$ \\
Weight loss & $5(4.9)$ \\
Anemia & $2(2.0)$ \\
Diarrhea & \\
\hline
\end{tabular}

lateral and supine positions. The third region was examined in the left lateral, right lateral and supine positions. The procedure was performed segment by segment. After the examination of a segment in the first position was completed, the colonoscope was reintroduced from the distal to the proximal site of that segment and the patient was examined in the other positions. The duration of examination was $2 \mathrm{~min}$ for each position, which was timed using a stopwatch. This led to a total withdrawal time of $14 \mathrm{~min}$ from the cecum to sigmoid colon-rectum junction excluding the time spent for position changes and therapeutic procedures. The size (estimated by comparing with open biopsy forceps), morphology (classified according to Paris classification) and location of all polyps were recorded after each position. Polyps were removed immediately after examination of that segment when all positions were completed. Polyps $<5 \mathrm{~mm}$ in size were removed by cold biopsy. Larger polyps were snared with electrocautery. ADR and PDR were defined as the proportion of cases with $\geq 1$ lesions detected. The histopathological diagnosis of polyps was assessed by experienced pathologists.

\section{Statistical methods}

Statistical analyses were performed using SPSS version 17.0 (IBM Corporation, USA) for Windows (Microsoft Corporation, USA). Values for continuous variables are presented as mean \pm SD while categorical variables are provided as percentages. Comparisons of continuous variables were made using the Student's $t$ test or Mann Whitney U-test, depending on normality of distribution. Categorical variables were compared using the Pearson's or Fisher's exact $\chi^{2}$ tests. The Wilcoxon signed-rank test and paired-samples test was used depending on the normality of distribution comparing two related samples to assess whether their population mean ranks differed; $\mathrm{P}<0.05$ was considered to be statistically significant.

\section{RESULTS}

A total of 120 patients were enrolled in the present study. Of these, $18(15 \%)$ patients were excluded because of poor bowel preparation in six $(5.0 \%)$, colitis in three $(2.5 \%)$, prolonged cecal intubation time in two $(1.7 \%)$, refusal to participate in one $(0.8 \%)$, musculoskeletal problems in two $(1.7 \%)$, inability to reach the cecum in one $(0.8 \%)$ and history of colon cancer in three (2.5\%) (Figure 1). Demographic and clinical characteristics of the remaining 102 patients who participated in the study are presented in Table 1.

Examination in the left lateral position revealed 66 polyps in 31 patients (PDR 30.3\%). The PDR increased to $43.1 \%$ ( 81 polyps in 44 patients) with additional examinations $(\mathrm{P}<0.001)$ (Table 2). The median size of the 15 polyps detected during additional position changes $(3 \mathrm{~mm})$ were smaller than those detected during examination in the left lateral position $(4 \mathrm{~mm})(\mathrm{P}=0.8)$. Ten were $<5 \mathrm{~mm}$, three 
TABLE 2

Polyps detected in the left lateral position (LLP) with or without position changes (PC)

\begin{tabular}{lccc}
\hline Location & LLP & LLP + PC & P \\
\hline Cecum & 14 & 14 & 1.0 \\
Ascending colon & 10 & 11 & 0.3 \\
Hepatic flexure & 2 & 3 & 0.3 \\
Transverse colon & 14 & 20 & 0.01 \\
Splenic flexure & 3 & 3 & 1 \\
Descending colon & 13 & 16 & 0.08 \\
Sigmoid colon & 10 & 14 & $0.04^{*}$ \\
Cecum + ascending + hepatic flexure & 26 & 28 & 0.5 \\
Transverse + splenic flexure + & 40 & 52 & $0.005^{\star}$ \\
$\quad$ descending + sigmoid & & & \\
Splenic flexure + descending + sigmoid & 26 & 33 & $0.02^{*}$ \\
Total & 66 & 81 & $<0.001^{*}$ \\
\hline
\end{tabular}

Data presented as $n$ unless otherwise indicated. *Statistically significant

TABLE 3

Adenomas detected in the left lateral position (LLP) with or without position changes (PC)

\begin{tabular}{lccl}
\hline Location & LLP & LLP + PC & P \\
\hline Cecum & 10 & 10 & 1.0 \\
Ascending colon & 6 & 6 & 1.0 \\
Hepatic flexure & 1 & 1 & 1.0 \\
Transverse colon & 11 & 16 & $0.05^{\star}$ \\
Splenic flexure & 1 & 1 & 1.0 \\
Descending colon & 8 & 10 & 0.1 \\
Sigmoid colon & 5 & 9 & $0.04^{*}$ \\
Cecum + ascending + hepatic flexure & 17 & 17 & 1.0 \\
Transverse + splenic flexure + descending + & 20 & 27 & 0.06 \\
$\quad$ sigmoid & & & \\
Splenic flexure + descending + sigmoid & 14 & 20 & $0.02^{*}$ \\
Total & 42 & 53 & $0.002^{*}$ \\
\hline
\end{tabular}

Data presented as $n$, unless otherwise indicated. *Statistically significant

were between $5 \mathrm{~mm}$ and $10 \mathrm{~mm}$, and two were $>10 \mathrm{~mm}$ in size. Paris classification was IIa in 10, IIb in three, and Is in two. The increase in the number of polyps was statistically significant in the transverse and sigmoid colon $(\mathrm{P}=0.01$ and $\mathrm{P}=0.04$, respectively).

Examination in the left lateral position revealed 42 adenomas in 11 female and 13 male patients. The ADR was 23.5\% (21.5\% for women and 25.4 for men). The ADR increased to $33.3 \%$ ( 53 adenomas in 34 patients) with the addition of position changes $(\mathrm{P}=0.002)$ (Table 3$)$. Seven of the additionally diagnosed 11 adenomas were $<5 \mathrm{~mm}$, three were between $5 \mathrm{~mm}$ to $10 \mathrm{~mm}$ and one was $14 \mathrm{~mm}$ in size. Paris classification was IIa in 8, IIb in two, and Is in one. None of the additionally diagnosed polyps had high-grade dysplasia or villous histology. The increase in the number of adenomas was statistically significant in the transverse and sigmoid colon ( $\mathrm{P}=0.05$ and $\mathrm{P}=0.04$, respectively).

The addition of position changes led to a $12.8 \%$ increase in the number of patients who had $\geq 1$ polyps detected in the transverse colon, splenic flexure, and descending and sigmoid colon (Table 4). Regarding ADR, there was a $9.8 \%$ increase in the number of patients with $\geq 1$ adenoma in the transverse colon, splenic flexure, descending and sigmoid colon (Table 5).

The frequency of surveillance interval determined according to The National Comprehensive Cancer Network (NCCN) Colorectal Cancer Screening Guidelines (13) was shortened in nine (8.8\%) patients (from 10 years to five years in two, from 10 years to three years in two, and from five years to three years in five patients) after examination of the colon in dynamic positions (Table 6).
TABLE 4

Patients in whom at least one polyp was detected in the left lateral position (LLP) with or without position changes (PC)

\begin{tabular}{lccc}
\hline Location & LLP & LLP + PC & P \\
\hline Cecum & $10(9.9)$ & $10(9.8)$ & 1.0 \\
Ascending colon & $8(7.8)$ & $9(8.8)$ & 0.1 \\
Hepatic flexure & $2(2.0)$ & $3(2.9)$ & 1.0 \\
Transverse colon & $10(9.8)$ & $16(15.7)$ & $0.01^{*}$ \\
Splenic flexure & $2(2.0)$ & $2(2.0)$ & 1.0 \\
Descending colon & $11(10.8)$ & $14(13.7)$ & 0.08 \\
Sigmoid colon & $8(7.8)$ & $12(10.8)$ & $0.04^{*}$ \\
Cecum + ascending + hepatic flexure & $20(19.6)$ & $22(21.4)$ & 0.1 \\
Transverse + splenic flexure + & $23(22.5)$ & $34(33.3)$ & $<0.001^{*}$ \\
$\quad$ descending + sigmoid & & & \\
Splenic flexure + descending + sigmoid & $18(17.6)$ & $26(25.5)$ & $0.003^{*}$ \\
\hline
\end{tabular}

Data presented as $n$ (\%) unless otherwise indicated. *Statistically significant

\section{TABLE 5}

Patients in whom at least one adenoma was detected in the left lateral position (LLP) with or without position changes (PC)

\begin{tabular}{lccc}
\hline Location & LLP & LLP + PC & P \\
\hline Cecum & $9(8.8)$ & $9(8.8)$ & 1.0 \\
Ascending colon & $5(4.9)$ & $5(4.9)$ & 1.0 \\
Hepatic flexure & $1(0.9)$ & $1(0.9)$ & 1.0 \\
Transverse colon & $9(8.8)$ & $13(12.7)$ & $0.04^{*}$ \\
Splenic flexure & $1(1.0)$ & $1(1.0)$ & 1.0 \\
Descending colon & $8(7.8)$ & $10(9.8)$ & 0.1 \\
Sigmoid colon & $5(4.9)$ & $9(8.8)$ & $0.02^{*}$ \\
Cecum + ascending + hepatic flexure & $15(14.7)$ & $15(14.7)$ & 1.0 \\
Transverse + splenic flexure + & $14(13.7)$ & $24(23.5)$ & $0.002^{*}$ \\
$\quad$ descending + sigmoid & & & \\
Splenic flexure + descending + sigmoid & $13(12.7)$ & $18(17.6)$ & $0.02^{*}$ \\
\hline
\end{tabular}

Data presented as $n(\%)$ unless otherwise indicated. *Statistically significant

TABLE 6

Change in the surveillance intervals of patients after addition of position changes (PC)

\begin{tabular}{lcl}
\hline Surveillance interval, years & LLP & LLP + PC \\
\hline 10 & $68(66.7)$ & $64(62.7)$ \\
5 & $26(25.5)$ & $23(22.5)$ \\
3 & $8(7.8)$ & $15(14.7)$ \\
\hline
\end{tabular}

Data presented as n (\%). LLP Left lateral position

\section{DISCUSSION}

The present study showed that dynamic position changes during colonoscopy withdrawal significantly improved ADR in the transverse colon, splenic flexure, and descending colon and sigmoid colon compared with examination in the left lateral position alone.

ADR is one of the most important quality measures of colonoscopy. An ADR of $\geq 25 \%$ in men and $\geq 15 \%$ in women $>50$ years of age is defined as acceptable (14). Lower ADR is associated with an increased interval of colon cancers (15). Various devices and methods have been used to improve ADR (2-11); however, dynamic position changes during colonoscopy withdrawal is one of the simplest. Position changes improve luminal distension, shift fluid away from the area of interest and open out flexures and angulations. The cecum, ascending colon and hepatic flexure are best visualized in the left lateral position, and the transverse colon supine and splenic flexure, descending and sigmoid colon in the right lateral position. However dynamic position changes are often ignored, possibly due to difficulty and reluctance in altering patient position, especially if sedated, and lack of endoscopist awareness. 
In the present study, ADR in the left lateral position was $25.4 \%$ for men and $21.5 \%$ for women. These values were close to the acceptable ADR threshold levels defined by societies. This may have been due to the enrollment of younger patients (40 to 50 years of age) in the study. Accordingly, the ADR in men and women $>50$ years of age were higher (30.8\% and $27.3 \%$, respectively) and consistent with values reported in guidelines. Dynamic position changes led to a $9.8 \%$ increase in the ADR. This finding is consistent with a recent study reporting an increase in ADR from 23\% in the left lateral position to 34\% after addition of position changes (16). The median size of the additionaly diagnosed adenomas were $3 \mathrm{~mm}$ and none exhibited high-grade dysplasia or villous histology. Although the benefit of removing these small adenomas in the short term may be limited, dynamic position changes led to a more accurate risk stratification for surveillance. The frequency of surveillance interval determined according to NCCN Colorectal Cancer Screening guidelines was shortened in nine (8.8\%) patients.

It is well known that ADR is strongly associated with longer colonoscopy withdrawal times. Studies have recommended that colonoscopy withdrawal should last at least $6 \mathrm{~min}$ (6). From this point of view, the increase in the ADR after dynamic position changes may be partly due to the significant increase in the colonoscopy withdrawal time due to position changes. On the other hand, ADRs in the cecum, ascending colon and hepatic flexure after examination in the left lateral position twice were almost identical, which suggests that prolonged withdrawal time is not the only factor contributing to increased ADR.

The increase in the number of adenomas detected after position changes were statistically significant in the transverse and sigmoid colon. The splenic flexure, descending and sigmoid colon were examined both in the supine and right lateral positions. The number of additional adenomas detected in the supine position (four adenomas) was equal to the number detected in the right lateral position. Although these position changes could be easily achieved in most of the unsedated or consciously sedated patients within a few seconds, it could be difficult to move a deeply sedated patient to the right lateral position. Therefore moving the patient only to the supine position

\section{REFERENCES}

1. van Rijn JC, Reitsma JB, Stoker J, Bossuyt PM, van Deventer SJ, Dekker E. Polyp miss rate determined by tandem colonoscopy: A systematic review. Am J Gastroenterol 2006;101:343-50.

2. Rex DK, Helbig CC. High yields of small and flat adenomas with high definition colonoscopes using either white light or narrow band imaging. Gastroenterology 2007;133:42-7.

3. Mamula P, Tierney WM, Banerjee S, et al. Devices to improve colon polyp detection. Gastrointest Endosc 2011;73:1092-7.

4. Rex DK, Chadalawada V, Helper DJ. Wide angle colonoscopy with a prototype instrument: Impact on miss rates and efficiency as determined by back-to-back colonoscopies. Am J Gastroenterol 2003;98:2000-5.

5. Harada Y, Hirasawa D, Fujita N, et al. Impact of a transparent hood on the performance of total colonoscopy: A randomized controlled trial. Gastrointest Endosc 2009;69:637-44.

6. Barclay RL, Vicari JJ, Doughty AS, Johanson JF, Greenlaw RL. Colonoscopic withdrawal times and adenoma detection during screening colonoscopy. N Engl J Med 2006;355:2533-41.

7. Rex D. Colonoscopic withdrawal technique is associated with adenoma miss rates. Gastrointest Endosc 2000;51:33-6.

8. Gurudu SR, Ramirez FC, Harrison ME, Leighton JA, Crowell MD. Increased adenoma detection rate with system-wide implentation of a split-dose preparation for colonoscopy. Gastrointest Endosc 2012;76:603-8.

9. Corte C, Dahlenburg L, Selby W, et al. Hyoscine butylbromide after examination of the hepatic flexure may be preferred and equally effective in deeply sedated patients. Examination of the entire colon in a specific position at once rather than examining segment by segment may be preferred in deeply sedated patients to prevent frequent position changes.

The present study had some limitations, the first of which was that it was a single-centre analysis; therefore, results should be confirmed in a larger, multicentre study. Although there is sufficient evidence that position changes increase ADR, additional studies investigating the benefit of only the supine position in the left colon may be useful. Another limitation was that the endoscopist was not blinded, which may have led to meticulous examination for additional polyp detection. Furthermore, examination of the colon segment by segment may have increased the awareness of the endoscopist to the polyps present in that segment in the first examination and led to easier detection of polyps at the dynamic position changes; however, randomization prevented the advantage of dynamic position changes. On the other hand, segmentary examination is more reflective of daily practice and decreases the time and effort needed for second intubation of the cecum. Antispasmodic medications and carbon dioxide insufflation were not used in any of the patients. Therefore, the results are widely generalizable.

\section{CONCLUSION}

Position changes during colonoscopy withdrawal led to a significant increase in the ADR in the transverse colon, splenic flexure, and descending and sigmoid colon. It is a simple and effective method to increase ADR. Endoscopists should integrate dynamic position changes into their routine clinical practice.

DISCLOSURES: The authors have no financial disclosures or conflicts of interest to declare.

administered at the cecum increases polyp detection: A randomized double-blind placebo-controlled trial. Endoscopy 2012;44:917-22.

10. Song LM, Adler DG, Conway JD, et al. Narrow band imaging and multiband imaging. Gastrointest Endosc 2008;67:581-9.

11. Kim TS, Park D, Lee DY, et al. Endoscopy nurse participation may increase the polyp detection rate by second-year fellows during screening colonoscopies. Gut Liver 2012;6:344-8.

12. Lai EJ, Calderwood AH, Doros G, Fix OK, Jacobson BC. The Boston bowel preparation scale: A valid and reliable instrument for colonoscopy-oriented research. Gastrointest Endosc 2009;69:620-5.

13. Burt RW, Barthel JS, Dunn KB, et al. Clinical practice guidelines in oncology. Colorectal cancer screening. J Natl Compr Canc Netw 2010;8:8-61.

14. Rex DK, Bond JH, Winawer S, et al. Quality in the technical performance of colonoscopy and the continuous quality improvement process for colonoscopy: Recommendations of the U.S. Multi-Society Task Force on Colorectal Cancer.

Am J Gastroenterol 2002;97:1296-308.

15. Kaminski MF, Regula J, Kraszewska E, et al. Quality indicators for colonoscopy and the risk of interval cancer. N Engl J Med 2010;362:1795-803.

16. East JE, Bassett P, Arebi N, Gibson ST, Guenther T, Saunders BP. Dynamic patient position changes during colonoscope withdrawal increase adenoma detection: A randomized, crossover trial. Gastrointest Endosc 2011;73:456-63. 


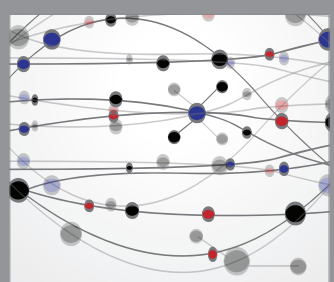

The Scientific World Journal
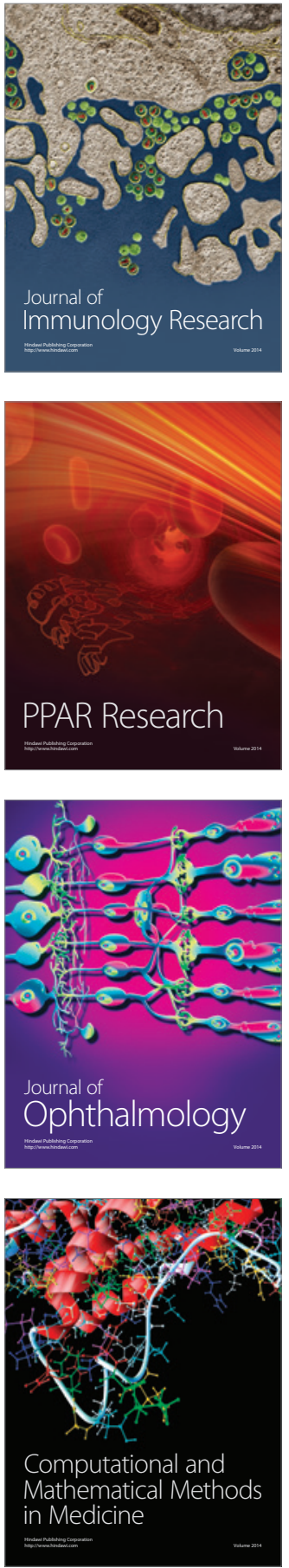

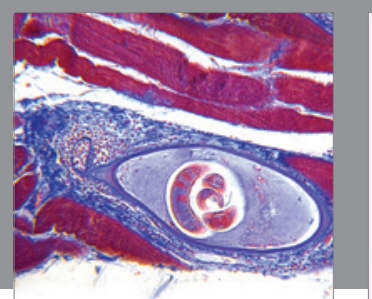

Gastroenterology Research and Practice

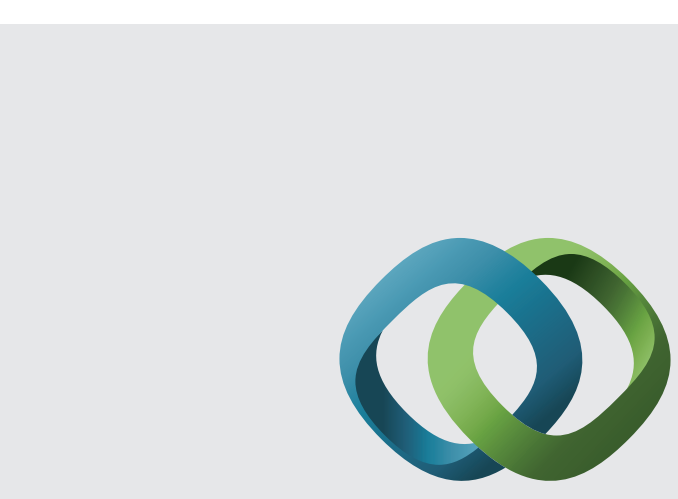

\section{Hindawi}

Submit your manuscripts at

http://www.hindawi.com
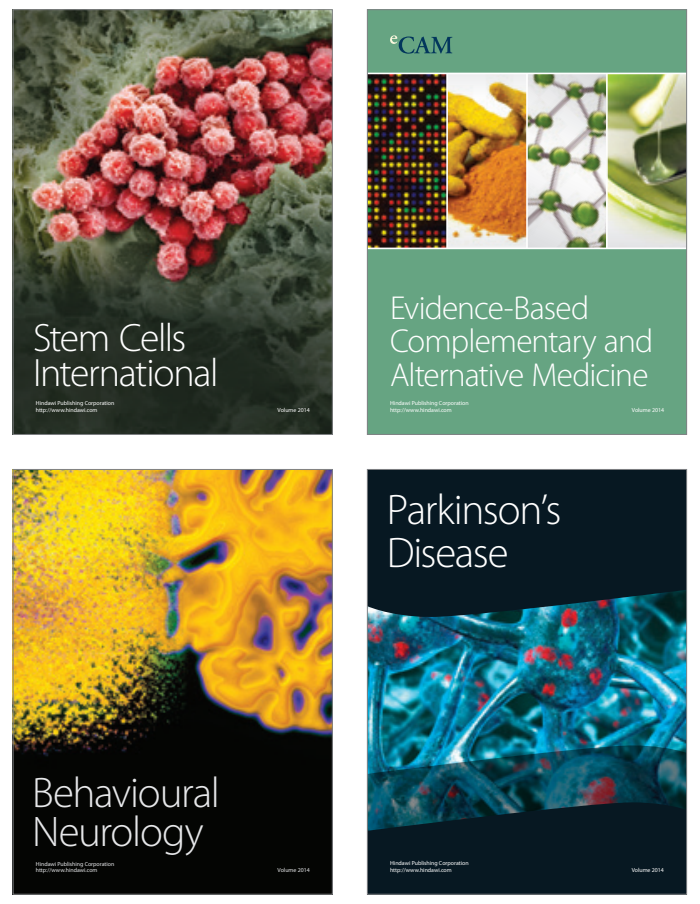
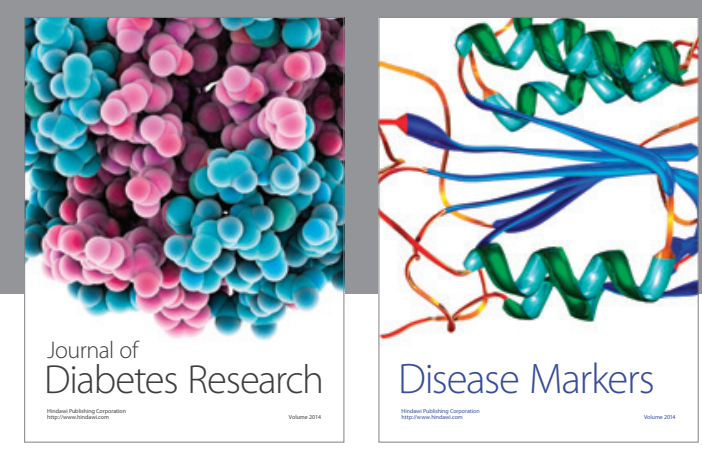

Disease Markers
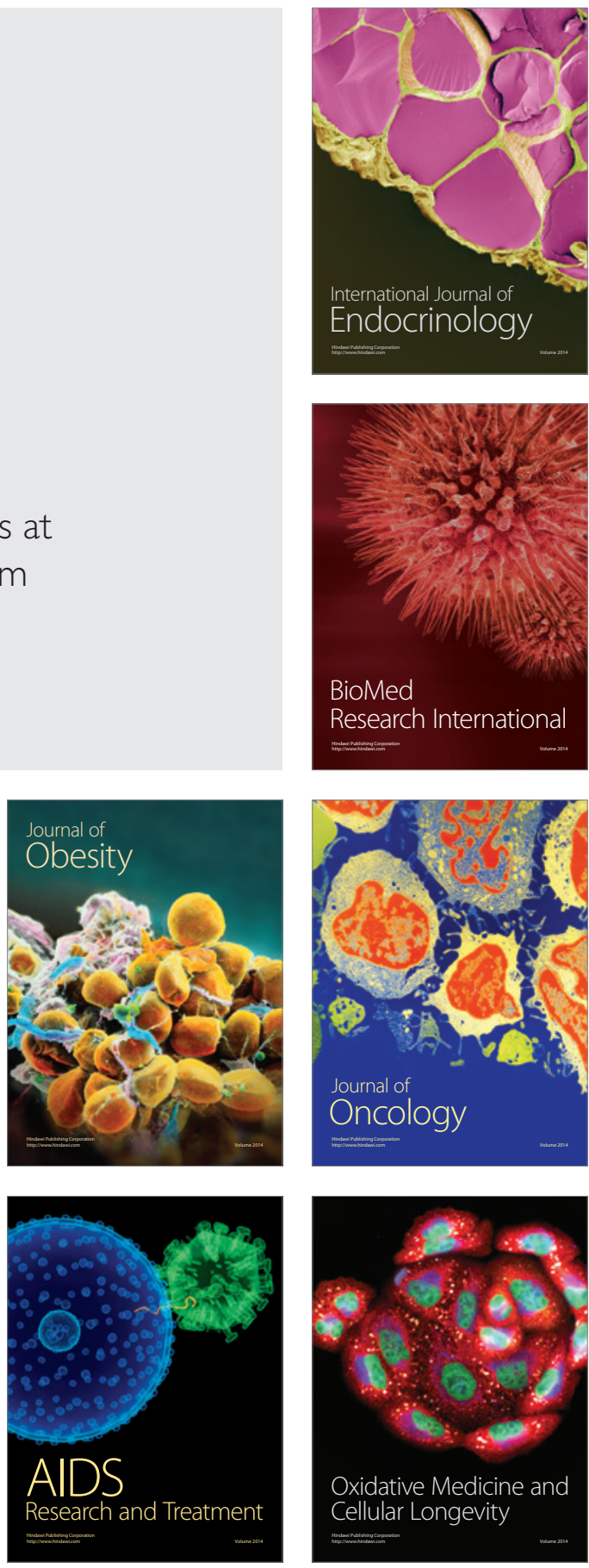